\title{
School Bullying: Empathy among Perpetrators and Victims
}

\author{
Carlos Salavera ${ }^{1,2} \mathbb{D}^{-}$, Pablo Usán ${ }^{1,2, *} \mathbb{C}$, Pilar Teruel ${ }^{1,2}$, Eva Urbón ${ }^{1,2}$ and Victor Murillo ${ }^{3}$ \\ 1 Research Group OPIICS, University of Zaragoza, 50009 Zaragoza, Spain; salavera@unizar.es (C.S.); \\ pteruel@unizar.es (P.T.); eurbon@unizar.es (E.U.) \\ 2 Faculty of Education, University of Zaragoza, 50009 Zaragoza, Spain \\ 3 Faculty of Health and Sports Sciences, University of Zaragoza, 22002 Huesca, Spain; vmurillo@unizar.es \\ * Correspondence: pusan@unizar.es
}

\section{check for} updates

Citation: Salavera, C.; Usán, P.; Teruel, P.; Urbón, E.; Murillo, V. School Bullying: Empathy among Perpetrators and Victims.

Sustainability 2021, 13, 1548. https://doi.org/10.3390/su13031548

Received: 8 December 2020

Accepted: 25 January 2021

Published: 2 February 2021

Publisher's Note: MDPI stays neutral with regard to jurisdictional claims in published maps and institutional affiliations.

\begin{abstract}
This study analyses the relationship between empathy and school bullying, taking both perpetrators and victims into consideration. The study sample comprised 840 students, 423 of which were female $(50.36 \%)$, aged an average of 14.28 years. The instruments used were an ad hoc questionnaire for socioeconomic variables and bullying behaviour, an empathy questionnaire, and a personality questionnaire. Victims yielded higher scores in terms of empathic concern, while both groups, aggressors and victims, yielded similar results in terms of cognitive and affective empathy. Concerning the correlation between these variables and personality, anxiety was found to be correlated with affective empathy and empathetic concern in both groups. A correlation between cognitive empathy and impulsiveness and activity was also found in both groups. Remarkably, aggression and cognitive empathy were found to be correlated, but only among victims. Finally, experiences with classmates, anxiety, sincerity, and aggression were found to act as predictors of school bullying, while gender and aggression factors were found to act as predictors among perpetrators, but to a lesser extent, which suggests that other factors must be in place for bullying behaviour to occur. The results suggest that, although empathy levels are different in both groups, they cannot act as a predictor of bullying, especially concerning perpetrators.
\end{abstract}

Keywords: empathy; assessment; perpetrators; victims; school bullying

\section{Affective Empathy, Cognitive Empathy, and Empathic Concern}

Empathy is the ability to understand other people's minds, to feel emotions other than our own, and to respond to them with concern and care for other people's suffering. It has commonly been defined as the ability to understand another person's feelings [1,2]. Empathy comprises two different but interrelated factors: affective empathy (the ability to understand other people's emotions) and cognitive empathy (a good understanding of other people's emotional states) [1]. During infancy, low empathy is related to poor relationships with peers, hostility, and intimidation $[3,4]$. During adolescence, low empathy leads to aggression and anti-social behaviour $[5,6]$. In adulthood, low empathy leads to child abuse, violence, and psychopathy. High empathy is related to social skills, problemsolving, and prosocial behaviour; both among children and adults, empathetic people are more likely to share resources, help those in need, and care for others [7].

Empathy plays a central role in the development of social behaviour. Initially, empathy was conceptualised from an affective perspective, and was regarded as a vicarious emotional response to others' emotions. Afterwards, it became clear that this one-dimensional perspective of empathy erroneously neglected the role played by cognition. Currently, empathy is considered a multi-dimensional concept, with both affective and cognitive dimensions [8].

Based on the definition above, we must distinguish between three different kinds of empathy: (1) Cognitive empathy, which is adopting the point of view of others and understanding their situation, emotions, and feelings. It involves putting oneself mentally 
in the place of other people without judging them from our own point of view. For instance, a student understands that one of their peers dresses differently or has a different hairstyle; (2) Emotional empathy, which is feeling what other people feel, and therefore understanding their emotions. For instance, a student tells their classmates about feeling lonely in class, and the rest end up crying in response to their classmate's suffering; and (3) Empathic concern, which is spontaneously offering help to those who are perceived to be in need. For instance, a student spontaneously offers to help an isolated classmate [9].

Research has shown that individuals with high levels of empathy are more prone to prosocial behaviour and altruism [10-12], whereas individuals with low empathy levels are more aggressive [13-15].

\section{School Bullying}

School bullying, also known as peer violence, is a form of recurrent and deliberate aggression by one or more perpetrators against a defenceless victim [16,17].

In a recent WHO-led study with 219,460 students from 42 countries, $11 \%$ of participants reported having been victims of school bullying at least four to six times during the two months prior to the survey, and $8.5 \%$ having taken part as perpetrators [18,19]. Bullying poses a high risk for the psychosocial development and academic performance of both perpetrators and victims [20-22], even among very young children [23]. Some studies include witnesses of bullying among those who are negatively affected by this behaviour [24,25].

The basic characteristics of school bullying are as follows [26]: (1) a victim is harassed by one or several aggressors, who have harmful intentions; (2) there is a power unbalance, physical or psychological, between victim and aggressor; (3) aggression is recurrent; and (4) the target is generally a single student. There are four basic forms of school bullying:

(1) physical: direct or indirect aggressive behaviour; (2) verbal: negative verbal behaviour; (3) social: isolating practices; and (4) psychological: insults, humiliations, undermining of self-esteem, and feelings of defencelessness. School bullying poses a risk to the personal, social, and academic development of both victims and aggressors. Bullying, far from decreasing, is on the increase, and is one of the main factors in school failure and dropout. Unfortunately, Spain is among the highest-scoring countries in these two variables.

\section{Empathy and School Bullying}

Traditional stereotypes define school bullies as anxious, insecure, academically mediocre students who are prone to resort to violence to solve conflicts, and cannot adequately process social information and solve social problems [27].

They have also been defined as socially competent, highly empathetic individuals who are capable of understanding the state of mind of their peers [28]. However, they struggle to assess the emotional consequences that their behaviour has on others, as well as to understand other people's emotions, and to share and empathise with others [29,30].

The different factors involved in school bullying lead to various emotional and behavioural problems. Bullies show higher tobacco and alcohol consumption rates, and are more prone to indulge in high-risk behaviours [31], as well as to anxiety and behavioural problems [32]. Victims are more prone to anxiety and depression [33].

Despite the low levels of empathy detected among aggressors, the capacity for empathetic response among these children has been paid little attention to date. Some studies have found a weak correlation between empathy and bullying, while other studies have argued that prosocial children were more empathic than aggressors, with no significant differences being found between victims and average students in terms of empathy [34].

Many studies have analysed school bullying and empathy in different educational tiers, but the causal role that empathy plays in school bullying has been paid less attention. A priori, empathy plays a key role in socialisation and interpersonal relationships [35]. Empathy contributes to prosocial behaviour [36,37], while low empathy is related to con- 
flictive behaviour such as aggression [38,39]. However, a recent meta-analysis [40] reached the surprising conclusion that empathy and aggression were only weakly correlated.

Associations between empathy and bullying have been reported. However, comprehensive analysis of the relationships between empathy and the aggressors and victims of such bullying is still lacking.

The main aim of this study was to assess empathy among perpetrators and victims. An existing gap in our knowledge which we aimed to cover concerns possible differences in empathy among aggressors and victims. In line with the theoretical background outlined above, the main hypothesis is that victims will show higher empathy levels than aggressors in all three dimensions: affective empathy, cognitive empathy, and empathetic concern.

Our second aim was to find predictors for school bullying, from the point of view of both aggressors and victims.

\section{Method}

\section{Participants}

The study sample comprised 840 subjects, 417 male (49.64\%) and 423 female (50.36\%), from six public secondary schools. The centres were selected by convenience sampling. The average age of participants was 14.28 years, ranging from 12 to 16, with a standard deviation of 1.426. One inclusion criterion was the ability to read and communicate in perfect Spanish in order to ensure that the questionnaire was perfectly understood and completed. Exclusion criteria included incomplete questionnaires. In addition, students with cognitive disorders were excluded from the study. Participation was voluntary. All respondents were volunteers, and parents and children signed an informed consent form. Questionnaires were distributed in class in the presence of the principal investigator. The questionnaires were collected individually as the students finished them, and reviewed to check for errors and to ensure that no questions were left unanswered.

The ethical guidelines of the Declaration of Helsinki and all ethical criteria of research with humans were met. The confidence level was $95 \%$ and the sampling error $5 \%$. It was thus concluded that the survey was representative of the province of Zaragoza (Spain). The survey was designed as a lateral study based on natural groups, because the groups were constituted by stable independent variables, without major cultural differences. Individual differences were compared, and dependent and independent variables recorded [41].

\section{Protocol}

The schools were contacted by phone and those that agreed to take part in the study were entered into a list. While handing out questionnaires, the aim of the survey was explained to participants and the importance that all questions be answered was stressed. Participants had $45 \mathrm{~min}$ to fill out the questionnaire and the informed consent form. The research protocol was endorsed by the OPIICS research group (S46_20R), Psychology and Sociology Department, Universidad de Zaragoza. They were reminded that all information collected was to be treated anonymously and confidentially. Parents and/or guardians also signed an informed consent form. The data was collected in October and November 2019.

\section{Instruments}

Bullying questionnaire [42].

The instrument used to compile information was an ad hoc questionnaire, which enabled us to put all participants at the same psychological level and tabulate answers for comparison [43].

The questionnaire was designed to take into consideration our general criteria and objectives. The main idea was to include questions related to aggression from the point of view of perpetrators, victims, and witnesses, while allowing us to detect certain factors that, according to the existing literature, can help to explain certain behaviours. This called for the inclusion of factors that have not been taken into consideration in previous questionnaires. 
The final questionnaire was divided into two sections: the first section compiled general information (age, gender, nationality, etc.) and the second section recorded bullyingrelated information.

Adolescent Measure of Empathy and Sympathy (AMES) [9], translated into Spanish [44].

This is a 12-item scale divided into three dimensions (cognitive empathy, affective empathy, and empathetic concern), with four items each. Participants must read a statement and express their degree of agreement with each element on a 5-point Likert scale: (1) strongly disagree, (2) disagree, (3) neutral, (4) agree, and (5) strongly agree. Cronbach $\alpha$ coefficients (cognitive empathy $=0.786$; affective empathy $=0.744$; empathic concern $=0.750$; total $=0.872$ ) were moderately high, which indicates good internal consistency in the questionnaire.

BFQ-NA personality questionnaire [45], translated into Spanish [46].

This questionnaire, also known as the Big Five Questionnaire for Children, is an adaptation of the classic Big Five Questionnaire for adults. The questionnaire's five dimensions are: conscience (autonomy, order, precision, rule-abiding, and commitment) $\alpha=0.81$; openness (intellectual aspects, creativity, and cultural interests) $\alpha=0.76$; extraversion (activity, enthusiasm, assertiveness, and self-confidence) $\alpha=0.73$; kindness (concern and sensitivity towards others and their needs) $\alpha=0.85$; and emotional instability (anxiety, depression, discontentedness, and anger) $\alpha=0.81$. The subject must respond to 65 items on a 5-point Likert scale (1-5). The questionnaire yielded a good reliability score $(\alpha=0.84)$.

\section{Data Analysis}

Descriptive statistics were used to outline the socio-demographic profile of the data and the various variables under study. Correlations among empathy, personality, and bullying variables were calculated prior to being processed and analysed with SPSS Statistical Package ver.26.0 software (IBM, Armonk, NY, USA). After performing normal distribution and equality of variances tests, we decided to use parametric techniques. Each variable was subject to descriptive analysis. In all cases, we used the lowest significance level possible. Bilateral tests were performed. For two-group hypothesis testing, we used Student's $t$-distribution. Cronbach's $\alpha$ was calculated to test the reliability of the test. Finally, perpetrator/victim predictor equations were established according to the remaining variables, through logistic regression using the stepwise method (forward path), based on Wald's statistics. Forward stepwise selection begins with a model containing no predictors, and then adds predictors to the model, one at a time, until all of the predictors are in the model. In particular, at each step, the variable that gives the greatest additional improvement to the fit is added to the model.

\section{Results}

A total of $23.96 \%(\mathrm{~N}=168 ; 72$ male and 94 female) of participants admitted to having bullied their peers, while $39.23 \%(\mathrm{~N}=275 ; 123$ male and 152 female) identified themselves as victims of bullying. These data were used to create two study groups: victims $(\mathrm{N}=275)$ and aggressors $(\mathrm{N}=168)$. Victims scored higher in all three empathic dimensions (cognitive empathy, affective empathy, and empathic concern) in the empathy questionnaire Table 1 Minor differences in effect size (Cohen's d) were found in the factor measuring empathic concern.

Table 1. Descriptors in the empathy questionnaire.

\begin{tabular}{cccc}
\hline Factors & M (ds) Victims & M (ds) Aggressors & Cohen's d \\
\hline Affective empathy & $13.92(2.48)$ & $13.65(2.59)$ & 0.10 \\
Cognitive empathy & $11.48(3.42)$ & $11.13(3.10)$ & 0.05 \\
Empathic concern & $16.54(2.78)$ & $15.84(2.90)$ & 0.24 \\
\hline
\end{tabular}


In addition, correlations between the empathy questionnaire and the BFQ-NA personality questionnaire Table 2 were calculated. The dimensions of the empathy questionnaire presented significant correlations with the other instruments.

Table 2. Correlations with personality factors (BFQ-NA).

\begin{tabular}{ccccccc}
\hline & \multicolumn{3}{c}{ Victims } & \multicolumn{3}{c}{ Aggressors } \\
\hline & $\begin{array}{c}\text { Cognitive } \\
\text { empathy }\end{array}$ & $\begin{array}{c}\text { Affective } \\
\text { empathy }\end{array}$ & $\begin{array}{c}\text { Empathic } \\
\text { concern }\end{array}$ & $\begin{array}{c}\text { Cognitive } \\
\text { empathy }\end{array}$ & $\begin{array}{c}\text { Affective } \\
\text { empathy }\end{array}$ & $\begin{array}{c}\text { Empathic } \\
\text { concern }\end{array}$ \\
\hline Anxiety & -0.085 & $-0.287^{* *}$ & $-0.322^{* *}$ & -0.084 & $-0.237^{* *}$ & $-0.244^{* *}$ \\
Impulsiveness & $-0.137^{*}$ & -0.098 & -0.082 & $-0.185^{* *}$ & -0.045 & -0.055 \\
Activity & $-0.183^{* *}$ & -0.088 & -0.012 & $-0.192^{* *}$ & -0.087 & -0.002 \\
Sincerity & -0.084 & -0.108 & 0.022 & -0.119 & -0.064 & 0.005 \\
Aggression & $-0.145^{*}$ & -0.106 & -0.065 & -0.089 & -0.060 & 0.040 \\
\hline${\text { Note: * } p>0.01^{* *} p>0.001}$ & & & & &
\end{tabular}

Finally, predictors for both victims and aggressors were calculated Table 3. This was carried out through a linear regression using the following factors: gender, empathy, personality and experience with classmates, teachers, and school.

Table 3. Predictor factors for victims and aggressors.

\begin{tabular}{|c|c|c|c|c|c|c|}
\hline & \multicolumn{3}{|c|}{ Victims } & \multicolumn{3}{|c|}{ Aggressors } \\
\hline & B (ET) & $t$ & $p$-Value & B (ET) & $t$ & $p$-Value \\
\hline Gender & $21.63(3.21)$ & 1.796 & 0.073 & $21.53(2.64)$ & 4.813 & $<0.001$ \\
\hline School experience & $0.68(0.38)$ & -1.726 & 0.085 & $1.48(0.31)$ & 0.629 & 0.529 \\
\hline $\begin{array}{l}\text { Classmate } \\
\text { experience }\end{array}$ & $-0.83(0.48)$ & -6.683 & $<0.001$ & $0.24(0.38)$ & -0.564 & 0.573 \\
\hline $\begin{array}{l}\text { Teachers } \\
\text { experience }\end{array}$ & $-2.98(0.45)$ & -0.61 & 0.542 & $-0.21(0.37)$ & -1.319 & 0.188 \\
\hline Empathy & $-0.27(0.44)$ & 1.561 & 0.119 & $-0.48(0.36)$ & -0.902 & 0.368 \\
\hline Anxiety & $0.49(0.05)$ & -2.429 & 0.015 & $0.15(0.04)$ & -0.25 & 0.803 \\
\hline Impulsiveness & $-0.17(0.07)$ & 0.437 & 0.662 & $-0.01(0.06)$ & -0.883 & 0.378 \\
\hline Activity & $0.04(0.08)$ & -1.515 & 0.13 & $-0.06(0.07)$ & 0.421 & 0.674 \\
\hline Sincerity & $-0.09(0.06)$ & 3.715 & $<0.001$ & $0.02(0.05)$ & 1.031 & 0.303 \\
\hline Aggression & $0.28(0.08)$ & -2.271 & 0.024 & $0.06(0.06)$ & -4.869 & $<0.001$ \\
\hline $\mathrm{R}^{2}(\%)$ & \multicolumn{3}{|c|}{45.7} & \multicolumn{3}{|c|}{10.9} \\
\hline Model & \multicolumn{3}{|c|}{$\mathrm{F}(11.701)=44.636 ; p<0.001$} & \multicolumn{3}{|c|}{$\mathrm{F}(11.701)=7.394 ; p<0.001$} \\
\hline
\end{tabular}

Note. B: Beta coefficient equal; E.T.: Error estimate $\mathrm{R}^{2}$ : R square; $t$ : t-value; $p$-Value: Signification.

A multiple regression was undertaken, taking gender, empathy, personality, and experience with classmates, teachers, and the school as predictor factors, and becoming a victim or an aggressor as criterion variables. Table 3 illustrates the results after entering the explicative variables, which were a significant factor in the prediction.

Concerning victims, predictors outlined were experience with classmates, anxiety, sincerity, and aggression factors, which account for a significant percentage of the variance $\left(R^{2}=45.7\right.$ in model $\left.\mathrm{F}(11.701)=44.636^{* * *}\right)$. Regarding aggressors, gender, and aggression factors were outlined as predictors, but less emphatically $\left(R^{2}=10.9\right.$, in model $\left.\mathrm{F}(11.701)=7.394^{* * *}\right)$.

\section{Discussion}

The first aim of this study was to assess empathy in school bullies and victims of school bullying. The second aim was to define factors to predict bullying from the point of view of both victims and aggressors.

A total of $24 \%$ of participants admitted to having bullied their classmates, while $39 \%$ characterised themselves as victims of this abuse. Concerning empathy in victims and 
aggressors, the study found no significant differences in terms of affective empathy and cognitive empathy. However, small differences were attested with regard to empathic concern, which, let us remember, is defined as a person's ability to detect when someone is in need, and to lend aid spontaneously and unconditionally. Previous studies reported that victims of bullying were more prone to show higher levels of empathic and cognitive empathy $[4,47,48]$, but less attention had hitherto been paid to empathic concern. The results suggest that victims show higher levels of empathic concern, perhaps as an indication of the help they would like to receive from their classmates [49].

Similarly, the correlations with personality-related data yielded similar results for both groups, except with regard to aggression. It can be concluded that anxiety presents a weak negative correlation with the factors used to measure affective empathy and empathic concern, suggesting that higher anxiety levels lead to less affective empathy and empathic concern, in line with recent studies $[9,50]$. On the other hand, impulsiveness and activity factors also present a negative correlation with cognitive empathy in both groups. Finally, aggression also presents a negative correlation with cognitive empathy, but only among victims, which suggests that low aggression levels led to greater cognitive empathy. This may be explained by the fact that empathy plays a key role in the way people deal with their emotions, which can also be affected by capacity, motivation, and context [36,51,52].

The analysis of the factors defined as predictors of bullying (from both the aggressor's and the victim's viewpoints) revealed that a negative experience with classmates and personality, anxiety, sincerity, and aggression factors increase the likelihood of becoming a victim by $45.7 \%$. Conversely, gender (male) and aggression were outlined in $10.9 \%$ as predictors of students becoming school bullies, as pointed out by previous studies [53]; it can be argued that the greater empathy detected among women acts as a barrier against these behaviours [54]. Although our results have outlined predictor factors for aggressors, they also suggest that other factors not taken into consideration help to turn students into bullies. This suggests an interesting research avenue for the future.

These results must be viewed in the light of the study's limitations. Although the sample is statistically relevant, it should be expanded to other social groups, among which the correlations between empathy and other constructs may be stronger. We should undertake longitudinal studies to assess empathy over a longer time period. In addition, empathy requires other abilities, for example in the realm of cognition, and this relationship should be explored. There is also room for improvement concerning the questionnaire.

Finally, this research presents various limitations: (1) the study is lateral, so no causal relationships can be inferred; and (2) data were based on self-reporting, which may introduce a factor of bias. Future research should explore these constructs more thoroughly with larger samples and also focus on special needs adolescent populations, for example students with anxiety and autism with different empathy profiles.

This sort of study can and should take into consideration other constructs such as affects, sense of humour, emotional intelligence, and social skills, all of which could be related to empathy and school bullying. The relationship of these constructs and school bullying should be explored; previous studies have focused on observed empathy levels and school bullying, and not in the way they relate to other factors.

\section{Conclusions}

The result of our study is a better understanding of empathy between victims and perpetrators of bullying, with direct implications for the school and the school system.

Our results have direct implications for educational strategies. Teachers and other members of the school community should work on empathy with young people from an early age, in order to help students and reduce bullying in the classroom. This can also help prevent poor academic performance and improve personal and academic development.

Programs led by education and school professionals can help students improve their school experience, contributing to the comprehensive development of students, preventing bullying and dropping out, and improving their academic performance. 
Our results encourage us to continue looking for new questions with which to develop new methodologies and find answers with which to contribute to the positive socialemotional development of adolescents.

Author Contributions: Conceptualisation: C.S., P.U., P.T., E.U. and V.M.; data curation, C.S., P.U., P.T., E.U. and V.M.; investigation, C.S., P.U., P.T., E.U. and V.M.; methodology, C.S., P.U., V.M. and P.T.; supervision, C.S., P.U., V.M. and P.T.; writing—original draft, C.S., P.U., P.T., E.U. and V.M.; writing-review and editing, C.S., P.U., P.T., E.U. and V.M. All authors have read and agreed to the published version of the manuscript.

Funding: This study was performed by Research Group OPIICS (S46_20R), University of Zaragoza (Zaragoza, Spain), and was supported by research funds provided by the Department of Science and Technology of the Government of Aragón (Spain) and the European Social Fund.

Institutional Review Board Statement: The study was conducted according to the guidelines of the Declaration of Helsinki, and approved by the Ethics Review Committee of OPIICS research group (S46_20R), Psychology and Sociology Department, Universidad de Zaragoza.

Informed Consent Statement: All respondents were volunteers, and parents and children signed an informed consent form.

Data Availability Statement: The data presented in this study are available on request from the corresponding author.

Conflicts of Interest: The authors declare no conflict of interest. The funders had no role in the design of the study; in the collection, analysis, or interpretation of data; in the writing of the manuscript; or in the decision to publish the results.

\section{References}

1. Cohen, D.; Strayer, J. Empathy in conduct-disordered and comparison youth. Dev. Psychol. 1996, 32, 988-998.

2. Smith, P.K. Violence in Schools: The Response in Europe; Routledge Falmer: London, UK, 2003.

3. Belacchi, C.; Farina, E. Feeling and thinking of others: Affective and cognitive empathy and emotion comprehension in prosocial/hostile preschoolers. Aggress. Behav. 2012, 38, 150-165. [CrossRef]

4. Estévez, E.; Jiménez, T.I.; Segura, L. Emotional intelligence and empathy in aggressors and victims of school violence. J. Educ. Psychol. 2019, 111, 488-496.

5. Salmon, S.; Turner, S.; Taillieu, T.; Fortier, J.; Afifi, T.O. Bullying victimization experiences among middle and high school adolescents: Traditional bullying, discriminatory harassment, and cybervictimization. J. Adolesc. 2018, 63, 29-40.

6. Stavrinides, P.; Georgiou, S.; Theofanous, V. Bullying and empathy: A short-term longitudinal investigation. Educ. Psychol. 2010, $30,793-802$.

7. Williams, A.; O'Driscoll, K.; Moore, C. The influence of empathic concern on prosocial behavior in children. Front. Psychol. 2014, 5, 425. [CrossRef]

8. Ang, R.P.; Goh, D.H. Cyberbullying among adolescents: The role of affective and cognitive empathy, and gender. Child. Psychiatry Hum. Dev. 2010, 41, 387-397. [CrossRef]

9. Vossen, H.G.M.; Piotrowski, J.T.; Valkenburg, P.M. Development of the Adolescent Measure of Empathy an Sympathy. Personal. Individ. Differ. 2015, 74, 66-71. [CrossRef]

10. Cuff, B.M.P.; Brown, S.J.; Taylor, L.; Howat, D.J. Empathy: A review of the concept. Emot. Rev. 2014, 8, 144-153. [CrossRef]

11. Spataro, P.; Calabro, M.; Longobardi, E. Prosocial behaviour mediates the relation between empathy and aggression in primary school children. Eur. J. Dev. Psychol. 2020. [CrossRef]

12. Telle, N.T.; Pfister, H.R. Positive empathy and prosocial behavior: A neglected link. Emot. Rev. 2014, 8, 154-163. [CrossRef]

13. Garaigordobil, M.; Martínez, V.; Aliri, J. Autoestima, empatía y conducta agresiva en adolescentes víctimas de bullying presencial. Eur. J. Investig. Health Psychol. Educ. 2013, 3, 29-40. [CrossRef]

14. Gutiérrez, M.; Escartí, A.; Pascual, C. Relaciones entre empatía, conducta prosocial, agresividad, autoeficacia y responsabilidad personal y social. Psicothema 2011, 23, 13-19.

15. Winter, K.; Spengler, S.; Bermpohl, F.; Singer, T.; Kanske, P. Social cognition in aggressive offenders: Impaired empathy, but intact theory of mind. Sci. Rep. 2017, 7, 670. [CrossRef]

16. Olweus, D. Bullying at School. What We Known and What We Can. Do; Blackwell: Oxford, UK, 1993.

17. Yung, H.Y.; Graham, S. Defending victims of bullying in early Adolescence: A multilevel analysis. J. Youth Adolesc. 2018, 47, 1926-1937. [CrossRef] 
18. Inchley, J.C.; Currie, D.B.; Young, T.; Samdal, O.; Torsheim, T.; Augustson, L.; Mathison, F.; Aleman-Diaz, A.Y.; Molcho, M.; Weber, M.; et al. Growing Up Unequal: Gender and Socioeconomic Differences in Young People's Health and Well-Being. Health Behaviour in School-Aged Children (HBSC) Study: International Report from the 2013/2014 Survey; WHO Publications: Copenhagen, Denmark, 2016.

19. Van der Ploeg, R.; Steglich, C.; Veenstra, R. The way bullying works: How new ties facilitate the mutual reinforcement of status and bullying in elementary schools. Soc. Netw. 2020, 60, 71-82. [CrossRef]

20. Olweus, D. Annotation: Bullying at school: Basic facts and effects of a school based intervention program. J. Child. Psychol. Psychiatry 1994, 35, 1171-1190.

21. Gomes, A.M.; Martins, M.C.; Farinha, M.; Silva, B.; Ferreira, E.; Caldas, A.C.; Brandao, T. Bullying's Negative Effect on Academic Achievement. Int. J. Educ. Psychol. 2020, 9, 243-268. [CrossRef]

22. Usán, P.; Salavera, C.; Teruel, P. School motivation, goal orientation and academic performance in secondary education students. Psychol. Res. Behav Manag. 2019, 12, 877-887.

23. Tanrikulu, I. Teacher reports on early childhood bullying: How often, who, what, when and where. Early Child. Dev. Care 2020, 190, 489-501. [CrossRef]

24. Rivers, I.; Poteat, V.P.; Noret, N.; Ashurst, N. Observing bullying at school: The mental health of implications witness status. Sch. Psychol. Q. 2009, 24, 211-223. [CrossRef]

25. Zych, I.; Ttofi, M.M.; Llorent, V.J.; Farrington, D.P.; Ribeaud, D.; Eisner, M.P. A longitudinal study on stability and transitions among bullying roles. Child. Dev. 2020, 91, 527-545. [CrossRef]

26. Garaigordobil, M. Prevalence and consequences of cyberbullying. A review. Int. J. Psychol. Psychol. Ther. 2011, 11, $233-254$.

27. Gini, G.; Albiero, P.; Benelli, B.; Altoé, G. Does empathy predict adolescents' bullying and defending behavior? Aggress. Behav. 2007, 33, 467-476.

28. Sutton, J.; Smith, P.K.; Swettenham, J. Social cognition and bullying: Social inadequacy or skilled manipulation. Br. J. Dev. Psychol. $1999,17,435-450$.

29. Espegale, D.L.; Hong, J.S.; Rao, M.A.; Low, S. Associations between peer victimization and academic performance. Theory Into Pract. 2013, 52, 233-240. [CrossRef]

30. Valdebenito, S.; Ttofi, M.; Eisner, M. Prevalence rates of drug use among school bullies and victims: A systematic review and meta-analysis of cross-sectional studies. Aggress. Violent Behav. 2015, 23, 137-146. [CrossRef]

31. Cerezo, F.; Méndez, I. Adolescentes, agresividad y conductas de riesgo de salud: Análisis de variables relacionadas. Int. J. Dev. Psychol. 2009, 1, 217-226.

32. Lara-Ros, M.R.; Rodriguez-Jimenes, T.; Martinez-Gonzalez, A.E.; Piqueras, J.A. Relación entre el bullying y el estado emocional y social en niños de educación primaria. Rev. De Psicol. Clínica Con Niños Y Adolesc. 2017, 4, 59-64.

33. Albores-Gallo, L.; Sauceda-Garcia, J.M.; Ruiz-Velasco, S.; Roque-Santiago, E. Bullying and its association with psychiatric disorders in a Mexican students sample. Salud Publica Mex 2011, 53, $220-227$.

34. Warden, D.; Mackinnon, S. Prosocial children, bullies and victims: An investigation of their sociometric status, empathy and social problem-solving strategies. Br. J. Dev. Psychol. 2003, 21, 367-385. [CrossRef]

35. Thompson, E. Empathy and consciousness. J. Conscious. Stud. 2000, 8, 1-32.

36. Lockwood, P.L.; Seararcardoso, A.; Viding, E. Emotion regulation moderates the association between empathy and prosocial behavior. PLoS ONE 2014, 9, 1051-1064.

37. Salavera, C.; Usán, P. Repercusión de las estrategias de afrontamiento de estrés en la felicidad de los alumnos de Secundaria. Rev. Electrónica Interuniv. De Form. Del Profr. 2017, 20, 65-77. [CrossRef]

38. Jolliffe, D.; Farrington, D.P. Examining the relationship between low empathy and bullying. Aggress. Behav. 2006, 32, 540-550.

39. Wai, M.; Tiliopoulos, N. The affective and cognitive empathic nature of the dark triad of personality. Personal. Individ. Differ. 2012, 52, 794-799.

40. Vachon, D.D.; Lynam, D.R.; Johnson, J.A. The (non)relation between empathy and aggression: Surprising results from a meta-analysis. Psychol Bull. 2014, 140, 751-773. [CrossRef]

41. Ato, M.; López, J.J.; Benavente, A. Un sistema de clasificación de los diseños de investigación en psicología. An. de Psicol. 2013, 29, 1038-1059. [CrossRef]

42. Salavera, C.; Usán, P.; Artal, P.; Gómez, J.; Modrego, R.; Suárez, H.; Calvo, N. Bullying in Primary and Secondary School in the view of University students. Eur. Proc. Soc. Behav. Sci. 2020, 295-300. [CrossRef]

43. Stoetzel, J.; Girard, A. Las Encuestas de Opinión Pública; Instituto de la Opinión Pública: Madrid, Spain, 1973.

44. Salavera, C.; Usán, P. Psychometric properties of empathy questionnaire for Spanish adolescents. Psicol. Reflexão E Crítica 2020, 33, 25. [CrossRef]

45. Barbaranelli, C.; Carpara, G.; Rabasca, A.; Pastorelli, C. A questionnaire for measuring the Big Five in late Childhood. Personal. Individ. Differ. 2003, 34, 645-664.

46. Del Barrio, M.V.; Carrasco, M.A.; Holgado, F.P. BFQ-NA Cuestionario de los Cinco Grandes para niños y Adolescentes (Adaptación a la Población Española); TEA Ediciones: Madrid, Spain, 2006.

47. van Noorden, T.H.J.; Cillessen, A.H.N.; Haselager, G.J.T.; Lansu, T.A.M.; Bukowski, W.M. Bullying involvement and empathy: Child and target characteristics. Soc. Dev. 2017, 26, 248-262. [CrossRef] 
48. Zych, I.; Baldry, A.C.; Farrington, D.P.; Llorent, V.J. Are children involved in cyberbullying low on empathy? A systematic review and meta-analysis of research on empathy versus different cyberbullying roles. Aggress. Violent Behav. 2019, 45, 83-97. [CrossRef]

49. Garandeau, C.F.; Vermande, M.M.; Reijntjes, A.H.A.; Arts, E. Classroom bullying norms and peer status: Effects on victim-oriented and bully-oriented defending. Int. J. Behav. Dev. 2019. [CrossRef]

50. Mitsopoulou, E.; Giovazolias, T. Personality traits, empathy and bullying behavior: A meta-analytic approach. Agression Violent Behav. 2015, 21, 61-72. [CrossRef]

51. Israelashvili, J.; Sauter, D.; Fisher, A. Two facets of Affective empathy: Concern and distress have opposite relationships to emotion recognition. Cogn. Emot. 2020. [CrossRef]

52. Salavera, C.; Usán, P.; Jarie, L. Emotional intelligence and social skills on self-efficacy in Secondary Education students. Are there gender differences? J. Adolesc. 2017, 60, 39-46. [CrossRef]

53. Lucas-Molina, B.; Pérez-Albéniz, A.; Fonseca-Pedrero, E.; Giménez-Dasi, M. Bullying, defending, and outsider behaviors: The moderating role of social status and gender in their relationship with empathy. Scand. J. Psychol. 2018, 59, 473-482. [CrossRef]

54. Mestre-Escrivá, M.V.; Samper-García, P.; Frías-Navarro, M.D.; Tur-Porcar, A.M. Are women more empathetic than men? A longitudinal study in Adolescence. Span. J. Psychol. 2009, 12, 76-83. [CrossRef] 